\title{
¿Toda actividad económica debe estar regulada? ${ }^{(*)}$
}

Hugo Gómez Apac

Abogado por la Universidad Nacional Mayor de San Marcos.

Magíster en Derecho de la Empresa por la Universidad Peruana de Ciencias Aplicadas. Profesor en la Maestría de Derecho de la Propiedad Intelectual y de la Competencia de la

Pontificia Universidad Católica del Perú.

Profesor en la Maestría de Derecho Administrativo Económico de la Universidad del Pacífico.

Profesor en la Maestría de Derecho Constitucional de la Universidad San Gregorio de

Portoviejo del Ecuador.

Profesor en la Escuela de Derecho de la Universidad Científica del Sur

Ex Secretario Técnico de la Comisión de Libre Competencia y de la Sala de Defensa de la

Competencia y ex Vicepresidente de la Comisión de Protección al Consumidor del Instituto

Nacional de Defensa de la Competencia y de la Protección de la Propiedad Intelectual.

SUMARI0:

I. Introducción.

II. La regulación de las actividades económicas.

III. La regulación debe ser eficaz y eficiente.

IV. El principio de proporcionalidad — 0 test de razonabilidad-

V. La ausencia de regulación como opción regulatoria.

VI. Conclusiones.

(*) Quito, 25 de abril de 2021. 


\title{
RESUMEN:
}

El presente ensayo reconoce la importancia de la regulación para evitar o minimizar que una actividad económica genere daños 0 externalidades negativas. Sin embargo, explica que instrumentos de manejo regulatorio como el régimen de eliminación de barreras burocráticas y el análisis de impacto regulatorio sostienen como una posibilidad la ausencia de regulación, lo que no significa ausencia de estado. Así, un escenario posible que los hacedores de políticas públicas deben tener presente es que, si las circunstancias lo justifican, una determinada actividad económica podría encontrarse exenta de regulación.

Palabras clave: Regulación, test de razonabilidad, externalidades negativas, barreras burocráticas, análisis de impacto regulatorio.

\begin{abstract}
:
This article recognizes de importance of regulation to avoid or minimize the negative externalities or damage that economic activities can generate. However, the article explains what regulatory management tools, such as the bureaucratic barriers elimination regime and the Regulatory Impact Assessment, claim as a possibility the lack of regulation, which does not mean the absence of the State. Thus, a possible scenario that public policymakers must consider is, that if the circumstances merit it, a certain economic activity could find itself exempt from regulation.

Keywords: Regulation, negative externalities, bureaucratic barriers, Regulatory Impact Assessment — RIA.
\end{abstract}

\section{INTRODUCCIÓN}

¿Toda actividad económica debe estar regulada? La primera respuesta que nos viene a la mente es afirmativa, que sí, pero ello deriva del sesgo cognitivo de aceptar como normal aquello a lo que ya estamos acostumbrados, y posiblemente estamos acostumbrados porque nosotros y nuestras conexiones familiares, amicales y profesionales lo consideramos razonable o correcto. Es como un círculo vicioso de auto-confirmación. Como en nuestro entorno observamos que en la práctica todas las actividades económicas están reguladas, nos parece natural que así sea y apostamos a que el sistema siga funcionando de esta manera. Sin embargo, una herramienta conceptual cada vez menos desconocida, que poco a poco se viene introduciendo en el ordenamiento jurídico peruano,' me refiero al Análisis de Impacto Regulatorio - en adelante, el $\mathrm{RIA}^{2}$ - , cuestiona el hecho de que toda actividad tenga que estar regulada. Según la metodología del RIA, una opción regulatoria es la ausencia de regulación.

Pues bien, el presente ensayo explica de qué manera instrumentos de mejora regulatoria reconocen que, en determinadas circunstancias, lo más beneficioso para la sociedad es que ciertas actividades económicas carezcan de regulación. Entendiendo la regulación como la decisión de la autoridad competente de establecer ex ante, es decir, antes de que el particular realice la actividad, cuáles son los requisitos y condiciones para que dicha actividad se desarrolle. Es necesario precisar esto porque la ausencia de regulación así entendida no significa la ausencia de intervención estatal.

Así, es factible que una determinada actividad económica no se encuentre sometida a la regulación - ex ante-, pero sí a otras modalidades de intervención del estado de carácter ex post, como la defensa de la libre y leal competencia,

1. Ver el literal c) del art. 5 del Decreto Legislativo 1448 - Decreto Legislativo que modifica el artículo 2 del Decreto Legislativo 1310, Decreto Legislativo que aprueba medidas adicionales de simplificación administrativa, y perfecciona el marco institucional y los instrumentos que rigen el proceso de mejora de calidad de regulatoria-, publicado en el diario oficial El Peruano el 16 de septiembre de 2018.

2. Por las siglas en inglés de Regulatory Impact Assessment. 
la tutela del consumidor y la efectividad de las reglas de responsabilidad civil.

\section{LA REGULACIÓN DE LAS ACTIVIDADES ECONÓMICAS}

El desarrollo de una actividad económica puede generar daños, tanto al que realiza la actividad, al que contrata con este y a terceros. Una persona que pinta edificios puede matarse si no usa arnés o este está mal colocado. Un peluquero en estado de ebriedad puede cortarle la oreja a su cliente. Un taxista conduciendo a excesiva velocidad puede atropellar a personas que cruzan la calzada. Hay actividades poco peligrosas que tienen la potencialidad de generar daños mínimos, mientras que otras son más peligrosas y pueden acarrear daños significativos. El servicio que brinda un psicólogo no es algo que deba preocuparnos demasiado. Si bien no le cortará la oreja a su cliente, un consejo inadecuado podría empeorar la conducta del paciente, como ponerlo más ansioso o nervioso de lo que estaba. La extracción de minerales, en cambio, mal desarrollada puede acarrear daños considerables. Los propios trabajadores podrían morir si utilizan incorrectamente los explosivos, y si no se toman las precauciones del caso, dicha actividad podría contaminar el aire y los recursos hídricos de la zona, poniendo en peligro la vida y salud de las personas y dañar los ecosistemas aledaños de manera irreparable. Una poza de relaves que se desmorona por haber sido mal construida podría matar a los propios trabajadores de la empresa minera y a poblaciones cercanas, así como contaminar el suelo y los ríos que atraviesan la avalancha del material tóxico.

Para evitar, mitigar y reparar tales daños, la administración pública despliega una serie de potestades administrativas que, bajo el término amplio de "regulación", regulan — valga la redundancia - el ejercicio de tales actividades, desde autorizar su inicio, establecer las reglas de su desarrollo y hasta cómo debe ser el final de la actividad. No todas las actividades reciben regulación en los tres aspectos inicio, desarrollo y fin-, pues ello va a depender de la magnitud de los daños y externali- dades negativas involucradas. Tratándose del servicio que brinda un psicólogo, la regulación se limita a controlar el inicio de la actividad, lo que se plasma con el título profesional a nombre de la nación que le concede la universidad en la que estudió psicología, y la licencia de funcionamiento de su consultorio que le otor-ADMINISTRATIVO ga la municipalidad. Si nos aseguramos de que el psicólogo cuenta con un título profesional otorgado por una universidad licenciada, podemos confiar en que no serán tan desacertados sus consejos. Y si su consultorio cuenta con licencia de funcionamiento municipal $-y$ autorización de defensa civil-, deberíamos confiar en que los pacientes acuden a un lugar seguro que cumple con las normas de seguridad e higiene pertinentes, así como las de zonificación y ornato de la ciudad. El desarrollo de la actividad no está sometida a regulación estatal, aunque probablemente el psicólogo deba cumplir, durante el desarrollo de su actividad, con las disposiciones de carácter ético establecidas por el Colegio de Psicólogos del Perú. En el caso de la actividad minera, debido a la posibilidad de provocar mayores y más nefastas externalidades negativas, la regulación incide en los tres aspectos. La empresa minera necesita cumplir con autorizaciones para iniciar su actividad, durante todo el desarrollo de esta debe cumplir con el estudio de impacto ambiental y las obligaciones ambientales y de seguridad establecidas en la regulación sectorial, y al terminar su actividad deberá tramitar su procedimiento de cierre de la mina a efectos de que la autoridad se asegure de que el socavón, el tajo abierto y las demás instalaciones cumplan los estándares ambientales y de seguridad correspondientes.

Los ejemplos mencionados evidencian que la regulación busca evitar, mitigar o reparar los costos que el ejercicio de una actividad económica puede producir a título de daño o externalidad. La regulación incide en tres aspectos de la actividad económica:

a) El inicio de la actividad: la regulación se expresa en autorizaciones, licencias de funcionamiento, permisos, registros habilitantes, la prohibición de actividades, etcétera.

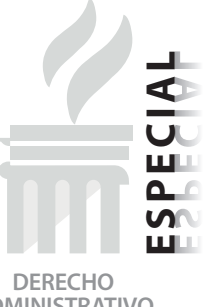


b) El desarrollo de la actividad: la regulación se manifiesta en el cumplimiento permanente de las condiciones establecidas en los actos administrativos habilitantes, en las normas sectoriales y en obligaciones convencionales - verbigracia contratos de concesión-y legales — verbigracia estudios de impacto ambiental-conducentes a proteger la vida y salud de las personas, sus bienes, el ambiente - los ecosistemas, la biodiversidad, los recursos naturales-, entre otros bienes jurídicos.

c) El final de la actividad: la regulación consiste en establecer condiciones para el cese y abandono de las operaciones. Es el caso, por ejemplo, de la autorización de cierre de una mina, de la aprobación del plan de abandono de una operación de extracción de hidrocarburos, etcétera.

\section{LA REGULACIÓN DEBE SER EFICAZ Y EFI- CIENTE}

Los ejemplos mencionados en el acápite anterior evidencian cómo la regulación establece los requisitos y condiciones para que una actividad económica se inicie, se desarrolle y culmine. Habrá casos en los que bastará regular el inicio de la actividad y en otras, en los que la potencialidad de que se generen externalidades negativas es mayor, también habrá que regular la culminación de la actividad.

Los ejemplos descritos también demuestran, en principio, que la regulación aparece como necesaria para evitar que el desarrollo de una actividad económica genere daños o externalidades negativas. Sin embargo, hay un asunto implícito que no se ha dicho, que es que la regulación tiene un costo. No solo el costo que significa para los privados "cumplir" los requisitos y condiciones, sino también el costo que implica que la administración pública haga "cumplir" la regulación. El enforcement de la regulación tiene siempre un costo alto. Decenas o centenas de burócratas tramitando permisos y procedimientos, realizando inspecciones y fiscalizaciones, imponiendo sanciones, etc.
Es fácil decir "regulemos la actividad", lo que ya no es tan fácil es diseñar una buena regulación. Dado que la regulación tiene un costo, lo mínimo a exigir es que este costo sea menor al beneficio que la regulación producirá en la sociedad. El remedio no puede ser peor que la enfermedad

La regulación debe ser eficaz, es decir, debe cumplir el propósito buscado. Por ejemplo, si la autoridad municipal detectara que ciertos establecimientos comerciales -como bares, licorerías y discotecas - están vendiendo bebidas alcohólicas a menores de edad, ¿qué regulación debería implementar para evitar estas ventas ilícitas? Asumamos que a la municipalidad se le ocurre restringir el horario de funcionamiento de tales establecimientos comerciales. Mediante ordenanza municipal prohíbe el funcionamiento de dichos establecimientos entre las 11:00pm y las 6:00am. ¿Esta regulación sería eficaz? ¿Al restringirse el horario de funcionamiento de los bares, licorerías y discotecas se lograría impedir la venta de bebidas alcohólicas a los menores de edad? Es evidente que no. Los empresarios inescrupulosos seguirían vendiendo licor a los menores de edad, no entre las 11:00pm y las 6:00am, sino antes de las 11:00pm. Podrían hacerlo a las 7:00pm, a las 9:00pm o a las 10:45pm. Es un claro ejemplo de una regulación no idónea. El objetivo perseguido, que es evitar la venta de licores a los menores, no se cumpliría. Lo peor es que "justos pagarían por pecadores", pues los establecimientos que no venden licor a los menores, es decir, que respetan la ley, se verían perjudicados al tener que cerrar a partir de las 11:00pm. Una respuesta administrativa diferente consiste en clausurar los establecimientos que violan la ley. Si la municipalidad implementara acciones de fiscalización y procediera a cerrar los locales que venden licor a menores de edad, el objetivo perseguido se cumpliría, sin afectar a los establecimientos que cumplen la ley. ¿Por qué una municipalidad escogería la primera opción, absolutamente ineficaz, y no la segunda? Por el costo que involucra implementar cada una de ellas. La primera es una prohibición generalizada, cuya implementación tiene un costo bajo: todos los negocios a partir de una determina- 
da hora deben estar cerrados. La segunda, en cambio, implica desarrollar un sistema de fiscalización focalizada que tenga por objeto atrapar a los infractores. Su implementación tiene un costo mayor, que probablemente implique usar a menores de edad como carnada, o incrementar las acciones de fiscalización establecimiento por establecimiento.

La regulación también debe ser eficiente. Y esto implica dos cosas. Primero, que la medida contenida en la regulación debe ser la opción menos gravosa de entre otras medidas igualmente idóneas; esto es, que de varias opciones, es la que impone menos costos a los administrados, o es la que restringe en menor medida la libertad económica. Segundo, que los beneficios de la regulación tienen que ser mayores a sus costos.

Asumamos que el Ministro de Transportes y Comunicaciones está cansado de que le reprochen todos los días por los muertos y heridos originados por los accidentes de tránsito. Como solución presenta un proyecto de ley que prohíbe la circulación de vehículos automotores en todo el territorio nacional. La propuesta prohíbe utilizar automóviles, camiones, buses, trenes, etcétera. La población tendría que caminar o usar bicicletas, caballos o carretas jaladas por caballos o burros. ¡Sí, una auténtica locura! Un retroceso de siglos. ¿La medida sería eficaz? Sí, en la medida que el objetivo es disminuir drásticamente el número de accidentes de tránsito, esto se va a cumplir. Al no haber vehículos, posiblemente el número de fallecidos baje de 3.000 al año a 30 o menos. Los pocos accidentes consistirán en ser pisoteado por un caballo o que dos carretas se choquen entre sí. La medida parece idónea para cumplir el objetivo perseguido, pero claramente resulta desproporcionada. ¿Hay una alternativa menos gravosa? Por supuesto, una auténtica fiscalización y sanciones ejemplares. Si cada vez que se detecta a un conductor en estado de ebriedad, conduciendo a excesiva velocidad, manejando un vehículo que no cumple las condiciones mínimas de seguridad, etcétera, se suspendiera su licencia de conducir y su vehículo fuera decomisado, las personas enmendarían su conducta y disminuirían los accidentes de tránsito. Esta segunda alternativa, qué duda cabe, constituye una opción menos gravosa. La primera opción, la prohibición absoluta de vehículos automotores, sería excesivamente costosa para la economía del país.

Finalmente, los costos de la regulación deben ser menores a sus beneficios. En el análisis costo-beneficio se debe sopesar todos los costos y beneficios, directos e indirectos, cuantitativos y cualitativos, y de corto, mediano y largo plazo. Asumamos que el Ministro de Salud desea promover el consumo de comida saludable y para tal efecto presenta al parlamento un proyecto de ley que no solo prohíbe la venta de comida con exceso de grasa, azúcar y sal en establecimientos abiertos al público, sino también prohíbe que dicha comida sea consumida en los hogares. Así es, estaría prohibido comer dentro de las casas hamburguesas, chicharrones, anticuchos, pizzas, embutidos, mantequilla, pasteles, postres y similares. El proyecto legislativo prevé la creación del Organismo Regulador de la Comida Saludable -ORCS. Este organismo, con oficinas descentralizadas en todo el país, supervisaría el cumplimiento de la ley. ¡Sí, otra auténtica locura! Todas las familias deberían informar al ORCS el último día del mes, por correo electrónico, llenando un formato aprobado por dicha entidad, lo que van a comer en el desayuno, almuerzo y cena de todos los días del mes siguiente. EI ORCS tendría que contratar a miles de servidores públicos para que revisen y registren los millones de formatos que se recibirían mensualmente, para procesarlos, registrarlos y obtener estadísticas, y a otros miles de fiscalizadores para que verifiquen in situ los hogares a efectos de cerciorarse de que lo que van a comer las personas guarde correspondencia con lo declarado en los formatos previamente entregados. Un ejército de decenas de miles de burócratas para cumplir el sueño del Ministro de Salud. Este alegará que, con el tiempo, disminuirá el sobrepeso, la hipertensión, las enfermedades cardiovasculares y hasta el cáncer, lo que podría medirse cualitativamente a través del menor número de atenciones médicas en los hospitales públicos y en el Seguro Social de Salud del Perú-EsSalud. La mejora de la

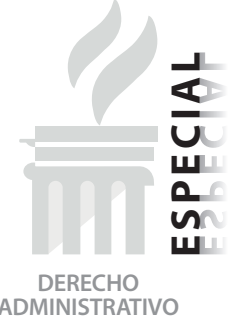

ADMINISTRATIVO 
salud de la población peruana es un beneficio que nadie dudaría en promover; sin embargo, habría que preguntarse sobre el costo de tan excéntrica medida. El costo que significaría el cierre de miles de restaurantes y cadenas de comida rápida, el costo de tiempo para todas las familias peruanas que tendrían que planificar e informar sobre lo que van a comer mes a mes, y el enorme impacto fiscal que significaría poner en funcionamiento el ORCS. Decenas de miles de millones de dólares en costos directos e indirectos. Una alternativa más razonable podría consistir en realizar campañas de educación conducentes a demostrar los beneficios de comer alimentos bajos en grasa, sal y azúcar.

¿Los ejemplos mencionados son estrambóticos, demasiado irreales? Lo cierto es que la realidad no se aleja mucho de ellos. El Instituto Nacional de Defensa de la Competencia y de la Protección de la Propiedad Intelectual-INDECOPI, ha declarado fundadas diversas denuncias presentadas contra municipalidades por la imposición de barreras burocráticas materializadas en la restricción del horario de funcionamiento de locales comerciales. ${ }^{3} \mathrm{~A}$ pesar de que hasta la fecha no se ha comprobado científicamente que los organismos vivos genéticamente modificados - OVM — sean dañinos para la biodiversidad, desde hace años están prohibidos en el Perú.

Mediante Ley $29811^{4}$ de diciembre de 2011 se estableció una moratoria de 10 años con el objeto de impedir el ingreso y producción en el territorio nacional de OVM con fines de cultivo o crianza, incluidos los acuáticos, a ser liberados en el ambiente. Dicha moratoria - que tiene por finalidad fortalecer las capacidades nacionales, desarrollar la infraestructura y general las líneas de base respecto de la biodiversidad nativa, que permitiera una adecuada evaluación de las actividades de liberación al ambiente de OVM - ha sido ampliada hasta finales del 2035 por la Ley 31111. ${ }^{5}$ ¡Estamos hablando de una prohibición de más de 24 años! ${ }^{6} Y$ en lo que se refiere a una propuesta cuyos costos serían mayores a sus beneficios, resulta pertinente traer a colación el Proyecto de Ley $123 / 2016-\mathrm{CR}^{7}$ que, entre otros, propuso modificar el artículo 152 del Código de

3. A modo de ejemplo, mediante Resolución № 1511-2009/SC1-INDECOPI de fecha 17 de diciembre de 2009 -Expediente 000173-2008/CEB—, la Sala de Defensa de la Competencia del Tribunal del Indecopi confirmó que la restricción de horarios en el distrito de Barranco constituía una barrera burocrática irrazonable debido a que limitaba no solo una zona específica de generación de ruidos molestos por aglomeración de locales de diversión, sino la totalidad del distrito.

4. Ley que establece la moratoria al ingreso y producción de organismos vivos modificados al territorio nacional por un periodo de 10 años, publicada en el diario oficial El Peruano el 9 de diciembre de 2011.

5. Ley que modifica la Ley 29811 , Ley que establece la moratoria al ingreso y producción de organismos vivos modificados al territorio nacional por un periodo de 15 años, a fin de establecer la moratoria hasta el 31 de diciembre de 2035, publicada en el diario oficial El Peruano el 6 de enero de 2021. Llama la atención que la Ley 31111 no fue promulgada por el Presidente de la República Francisco Rafael Sagástegui Hochhausler, sino por la Presidenta interina del Congreso de la República Mirtha Esther Vásquez Chuquilin.

6. Entendemos que, en aplicación del principio precautorio y ante la falta de certeza científica respecto del presunto daño que los OVM podrían generar sobre la biodiversidad, se justificaba una moratoria conducente a fortalecer las capacidades nacionales, desarrollar la infraestructura y generar las líneas de base respecto de la biodiversidad nativa, con el objeto de permitir una adecuada evaluación de las actividades de liberación al ambiente de OVM; sin embargo, una prohibición de más de 24 años revela una gestión pública con dificultades para determinar de una vez por todas si los OVM son susceptibles o no de dañar la biodiversidad. En todo caso, nada impide que las autoridades nacionales competentes aceleren los estudios e investigaciones a su cargo a efectos de encontrar cuanto antes una respuesta a la interrogante.

7. Presentado el 24 de agosto de 2016. 
Protección y Defensa del Consumidor ${ }^{8}$ a efectos de que en el plazo de 72 horas todas las quejas o reclamos consignados en el libro de reclamaciones $^{9}$ sean remitidos al INDECOPI. Según el texto vigente de dicho artículo, dichas quejas o reclamos son puestos a conocimiento del INDECOPI en dos circunstancias: (i) cuando el INDECOPI los requiera de oficio; $y$, (ii) cuando el consumidor ha presentado una denuncia, y en el procedimiento sancionador correspondiente el proveedor denunciado remite la copia de la queja o reclamo consignado en el libro de reclamaciones junto con sus descargos. ${ }^{10}$

Lo que el mencionado proyecto de ley olvida es que no todo reclamo o queja amerita el inicio de un procedimiento sancionador, pues ello depende principalmente de la voluntad del consumidor. Si, por ejemplo, un consumidor anota en el libro de reclamaciones que la sopa servida en el restaurante estaba muy fría, podría contentarse con la disculpa ofrecida por el conductor del negocio, quien seguramente tendrá en cuenta la queja para mejorar su servicio. $Y$ así como la sopa fría deben haber miles y hasta decenas de miles de reclamos por situaciones incómodas pero insignificantes. Es el consumidor el que decide si encontrar un pelo o una mosca en la ensalada amerita o no pagar la tasa administrativa para la interposición de una denuncia formal contra el proveedor, sin perjuicio de su derecho a anotar su disconformidad en el libro de reclamaciones, y sin perjuicio de la potestad del INDECOPI de exigir a cualquier proveedor que le remita copia del contenido del mencionado libro. Como puede apreciarse, no todo reclamo o queja consignado en el libro de reclamaciones conlleva un análisis por parte del INDECOPI.

DERECHO
MINISTRATIVO

Sin embargo, el proyecto de ley lo que plantea-
ba era que todos los establecimientos comerciales tenían la obligación de remitir al Indecopi la documentación correspondiente al libro de reclamaciones en el término de 72 horas de formulada la queja o reclamo, y que el INDECOPI podía iniciar un procedimiento sancionador comunicando a las partes su decisión. Según la propuesta legislativa, las decenas de miles de quejas o reclamos consignados en los libros de reclamaciones deberían ser puestos en conocimiento del INDECOPI. Un costo para todos los establecimientos comerciales, quienes tendrían que informar a la autoridad de protección al consumidor de todas las quejas recibidas, incluyendo aquellas que no revisten mayor interés para el consumidor. No solo eso, 72 horas constituiría un plazo insuficiente para resolver de motu proprio los reclamos de carácter complejo." Pero el costo mayor sería para la autoridad. El INDECOPI tendría que evaluar decenas de miles de quejas, sin más fundamento que lo consignado en el libro de reclamaciones, para determinar si existen o no indicios razonables que justifiquen el inicio de un procedimiento sancionador. Absolutamente desproporcionado. Es manifiestamente evidente que los costos serían mayores a los beneficios.

8. Aprobado por Ley 29571, publicado en el diario oficial El Peruano el 2 de septiembre de 2010.

9. Según los artículos 150 y 151 del Código de Protección y Defensa del Consumidor, todos los establecimientos comerciales deben contar con un libro de reclamaciones, en forma física o virtual, y lo deben exhibir en un lugar visible y fácilmente accesible al público, así como exhibir un aviso que indique la existencia del referido libro y el derecho que tienen los consumidores de solicitarlo cuando lo estimen conveniente.

10. Código de Protección y Defensa del Consumidor:

"Artículo 152.- Entrega del libro de reclamaciones

Los consumidores pueden exigir la entrega del libro de reclamaciones para formular su queja o reclamo respecto de los productos o servicios ofertados. Los establecimientos comerciales tienen la obligación de remitir al Indecopi la documentación correspondiente al libro de reclamaciones cuando éste le sea requerido. En los procedimientos sancionadores, el proveedor denunciado debe remitir la copia de la queja o reclamo correspondiente junto con sus descargos."

11. Por ejemplo, la compra de un automóvil. 
La norma vigente, en cambio, resulta más razonable. Es el consumidor el que mide su insatisfacción personal y elige si denuncia o no, caso en el cual presentará una copia del reclamo consignado en el libro - pues tiene derecho a que se lo entreguen-, o será el proveedor denunciado quien presente dicha copia al presentar sus descargos en el procedimiento sancionador - pues así lo ordena el artículo 152 del Código de Protección y Defensa del Consumidor-, sin perjuicio de que, a través de una acción de fiscalización de oficio, el Indecopi exija a cualquier proveedor la entrega de una copia del libro de reclamaciones. Para beneficio de proveedores e Indecopi, el Proyecto de Ley $123 / 2016-C R$ no ha sido aprobado hasta la fecha.

\section{EL PRINCIPIO DE PROPORCIONALIDAD -O TEST DE RAZONABILIDAD-}

En la sección precedente se ha señalado que la regulación debe ser eficaz, esto es, "idónea" para el propósito buscado, y además eficiente, es decir, "ser la opción menos gravosa" entre otras alternativas igualmente idóneas y tener "más beneficios que costos". Estas exigencias, que son de sentido común, son las previstas en el principio de proporcionalidad, el cual, en palabras de Ramsis Ghazzaoui, constituye la condición de validez de las normas limitadoras de derechos fundamentales. ${ }^{12}$ Como bien lo explica este autor, cualquier medida estatal que pretenda limitar derechos constitucionales $-y$ la regulación lo que limita son los derechos fun- damentales de la libre iniciativa privada y la libertad de empresa, que en conjunto podemos llamar "libertad económica"- debe cumplir los siguientes tres sub-principios del principio de proporcionalidad: ${ }^{13}$

a) Juicio de adecuación o idoneidad: La medida debe tener la aptitud de cumplir la finalidad ${ }^{14}$ perseguida. Debe existir un nexo causal que dirija la acción de la medida restrictiva hacia la consecución de la finalidad buscada. ${ }^{15}$

b) Juicio de necesidad o la medida menos restrictiva: No existe una alternativa menos lesiva pero igualmente eficaz. No es admisible la restricción del derecho a menos que sea estrictamente indispensable o necesario, en el sentido de que no existen otras medidas alternativas igualmente idóneas que, sin comprometer ese fin inicialmente previsto, afecten en menor grado el derecho cuya restricción se pretende. $^{16}$

c) La proporcionalidad en sentido estricto o balance costo-beneficio: La medida restrictiva del derecho fundamental debe ser proporcional con la finalidad perseguida. Este sub-principio es el componente más exigente y comprensivo del juicio de la prohibición de exceso. ${ }^{17}$ Los beneficios deben ser mayores a los costos.

El principio de proporcionalidad -o test de

12. Ramsis Ghazzaoui, Propiedad y Expropiación. Un estudio comparado entre los ordenamientos de España y Venezuela, Tirant lo Blanch. (Valencia, 2020) P. 63.

13. Ibíd, pp. 63-73.

14. Un elemento intrínseco al primer sub-principio es que la medida limitadora del derecho fundamental debe tener una finalidad acorde con el ordenamiento constitucional.

15. Ghazzaoui, Propiedad y Expropiación... p. 68.

16. Ibíd, p. 69.

17. Ibíd, p. 71. 
razonabilidad - ha sido ampliamente aplicado por el Tribunal Constitucional. ${ }^{18}$ Luis Castillo-Córdova explica que este principio tiene una lógica interna en la determinación de la existencia de esa adecuada relación entre lo sacrificado y la finalidad del sacrificio que exige someter la medida - o acto- que restringe el derecho a un triple juicio: ${ }^{19}$

\section{“...Juicio de idoneidad}

El juicio de idoneidad tiene una doble exigencia. En primer lugar requiere que la medida o acto de limitación del derecho constitucional tenga un fin constitucionalmente permitido $y$ socialmente relevante; $y$ en segundo lugar exige que la medida en sí misma sea adecuada para el logro de ese fin...

\section{...Juicio de necesidad}

Si la medida que afecta un derecho fundamental ha superado el juicio de idoneidad no por ello es necesariamente una medida que se ajuste al principio de proporcionalidad, sino que ha de superar - como siguiente paso- el juicio de necesidad. Este juicio, también Ilamado juicio de indispensabili- dad, consiste en examinar si la medida que se evalúa es la menos restrictiva del derecho fundamental que otras medidas igualmente eficaces...

....El principio de proporcionalidad en sentido estricto

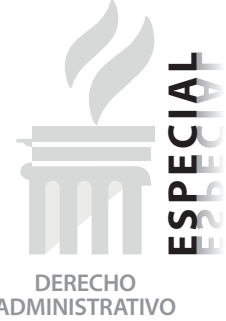

\section{A) Relación razonable}

Si la medida que afecta el derecho fundamental supera el juicio de idoneidad y el juicio de necesidad, no significa con ello que se esté delante de una medida proporcional. Esa medida debe aprobar un juicio más, el llamado juicio de proporcionalidad en sentido estricto. Este juicio exige que la medida cuestionada guarde una relación razonable con el fin que se pretende alcanzar. Generalmente se admite que se está frente a una relación razonable cuando existe un equilibrio entre las ventajas o beneficios y entre las desventajas o los costos de adoptar la medida enjuiciada.

(...)

B) Juicio complementario: el contenido constitucional de los derechos fundamentales

18. Así, por ejemplo, en la Sentencia de fecha 3 de junio de 2005, recaída en los Expedientes acumulados 050-2004$\mathrm{Al} / \mathrm{TC}$ y otros - Proceso de inconstitucionalidad contra la Ley 28389, de reforma constitucional de régimen pensionario, y contra la Ley 28449, de aplicación de nuevas reglas pensionarias previstas en el Decreto Ley 20530-, el Tribunal Constitucional señaló lo siguiente en el fundamento 109.

"El test de razonabilidad es un análisis de proporcionalidad que está directamente vinculado con el valor superior justicia; constituye, por lo tanto, un parámetro indispensable de constitucionalidad para determinar la actuación de los poderes públicos, sobre todo cuando ésta afecta el ejercicio de los derechos fundamentales. Para que la aplicación del test sea adecuada, corresponde utilizar los tres principios que lo integran. De acuerdo con el principio de idoneidad o adecuación, toda injerencia en los derechos fundamentales debe ser idónea para fomentar un objetivo constitucionalmente legítimo, suponiendo dos cosas: primero, la legitimidad constitucional del objetivo y, segundo, la idoneidad de la medida sub examine. El principio de necesidad significa que, para que una injerencia en los derechos fundamentales sea necesaria, no debe existir ningún otro medio alternativo que revista, por lo menos, la misma idoneidad para alcanzar el objetivo propuesto y que sea más benigno con el derecho afectado. Requiere analizar, de un lado, la idoneidad equivalente o mayor del medio alternativo, y, de otro, el menor grado en que éste intervenga en el derecho fundamental. Por último, de acuerdo con el principio de proporcionalidad en strictu sensu, para que una injerencia en los derechos fundamentales sea legítima, el grado de realización del objetivo de ésta debe ser por lo menos equivalente o proporcional al grado de afectación del derecho fundamental, comparándose dos intensidades o grados: el de la realización del fin de la medida examinada y el de la afectación del derecho fundamental."

19. Luis Castillo-Córdova. El principio de proporcionalidad en la jurisprudencia del Tribunal Constitucional peruano, en Revista Peruana de Derecho Público (Administrativo y Constitucional), (Lima: Editora Jurídica Grijley, Año 6, núm. 11, julio-diciembre de 2005) P. 137. 
Definida como se ha hecho la relación razonable debe llegarse a admitir que a mayor beneficio se permitirá un mayor costo. Es decir, este juicio permite concluir que una medida es razonable si se produce una afectación del derecho fundamental en un grado similar al grado de beneficio que se obtiene con la consecución de la finalidad. Pero la aplicación estricta de esta concepción costo-beneficio corre el riesgo de que con su ejecución se termine vulnerando derechos fundamentales... (...)

Este riesgo, sin embargo, puede ser controlado si al principio de razonabilidad o proporcionalidad se le añade un último juicio: el del contenido esencial de los derechos fundamentales. Este juicio afirma que todo derecho fundamental cuenta con un contenido constitucional, el cual es único, limitado, ilimitable y delimitable. En ningún caso, por tanto, podrá justificarse un beneficio que afecte al derecho constitucional en su contenido esencial..."

¿Qué sucede si una medida limitadora o restrictiva de un derecho constitucional no supera el test de razonabilidad —o principio de proporcionalidad-? La respuesta es que dicha medida resulta inconstitucional por violar el principio de proporcionalidad.

El mencionado test de razonabilidad ha sido incorporado dentro del análisis de razonabilidad que debe efectuar la Comisión de Eliminación de Barreras Burocráticas del Indecopi al momento de examinar la barrera burocrática ${ }^{21}$ denunciada, tal como se aprecia del artículo 18 de la Ley de Prevención y Eliminación de Barreras Burocráticas, ${ }^{22}$ que se cita a continuación:

\section{"Artículo 18.- Análisis de razonabilidad}

18.1. Una vez que la Comisión o la Sala, de ser el caso, considera que han sido presentados indicios suficientes sobre la presunta carencia de razonabilidad de la barrera burocrática cuestionada, analiza la razonabilidad de la medida, verificando el cumplimiento de los siguientes elementos:

a. Que la medida no es arbitraria, lo que implica que la entidad acredite:

1. La existencia del interés público que sustentó la medida cuestionada. El interés público alegado debe encontrarse dentro del ámbito de atribuciones legales de la entidad.

2. La existencia del problema que se pretendía solucionar con la medida cuestionada.

3. Que la medida cuestionada resulta idónea o adecuada para lograr la solución del problema y/o para alcanzar el objetivo de la medida.

b. Que la medida es proporcional a sus fines, lo que implica que la entidad acredite:

1. Una evaluación de los beneficios y/o el impacto positivo que generaría la medida y de los costos y/o el impacto negativo de la misma para los agentes económicos obligados a cumplirla, así como para otros agentes afectados y/o para la competencia en el mercado.

20. Ibíd, pp. 137-142.

21. El artículo 3 de la Ley de Prevención y Eliminación de Barreras Burocráticas define a la "barrera burocrática" como toda exigencia, requisito, limitación, prohibición y/o cobro que imponga cualquier entidad, dirigido a condicionar, restringir u obstaculizar el acceso y/o permanencia de los agentes económicos en el mercado y/o que puedan afectar a administrados en la tramitación de procedimientos administrativos sujetos a las normas y/o principios que garantizan la simplificación administrativa. La sola calidad de exigencia, requisito, limitación, prohibición y/o cobro no implica necesariamente su carácter ilegal y/o su carencia de razonabilidad.

22. Aprobada por Decreto Legislativo 1256, publicado en el diario oficial El Peruano el 8 de diciembre de 2016. 
2. Que la referida evaluación permite concluir que la medida genera mayores beneficios que costos.

3. Que otras medidas alternativas no resultarían menos costosas o no serían igualmente efectivas. Dentro de estas medidas alternativas debe considerarse la posibilidad de no emitir una nueva regulación.

18.2. En caso de que la entidad no acredite alguno de los elementos indicados en los literales precedentes, la Comisión o la Sala, de ser el caso, declara la carencia de razonabilidad de la barrera burocrática." (Subrayado añadido)

En el test de razonabilidad previsto en el artículo 18 de la Ley de Prevención y Eliminación de Barreras Burocráticas aparecen los juicios de idoneidad y de necesidad y el principio de proporcionalidad en sentido estricto - el análisis costo-beneficio-, aunque no en el orden explicado por Ramsis Ghazzaoui, Luis Castillo-Córdova y el Tribunal Constitucional. Los tres sub-principios del principio de proporcionalidad se encuentran presentes en el contexto de un análisis más integral y exigente, y desde un enfoque que complementa lo jurídico con lo económico, lo que resulta más apropiado para el análisis de la regulación administrativa, es decir, las barreras burocráticas establecidas por los órganos u organismos de la administración pública.

\section{LA AUSENCIA DE REGULACIÓN COMO OPCIÓN REGULATORIA}

En el numeral 3 del literal b) del numeral 18.1 del artículo 18 de la Ley de Prevención y Eliminación de Barreras Burocráticas, citado en al acápite precedente, y en lo referido al juicio de necesidad — que tiene por objeto indagar si hay otras medidas menos gravosas o costosas pero igualmente efectivas -idóneas - para cumplir la finalidad de la medida restrictiva del derecho-, se menciona claramente que dentro de estas medidas alternativas debe considerarse la posibilidad de no emitir una nueva ADMINISTRATIVO regulación.

Como puede apreciarse, una norma con rango de ley -Decreto Legislativo 1256 - reconoce de manera expresa como una posibilidad, en manos de los hacedores de la regulación, el no emitir una nueva regulación, lo que significa que la actividad económica que se encontraba sometida a una regulación deje de estarlo. Una opción de la autoridad administrativa es no regular una determinada actividad económica. Este escenario no debe espantarnos. Todo lo contrario. Es preferible que una actividad no esté regulada a que se expida una regulación ineficaz o ineficiente. No debe perderse de vista que la ausencia de regulación no significa la ausencia de intervención estatal. Una actividad económica podría encontrarse libre de regulación, pero sometida a un control ex post por parte de las normas de defensa de la libre y leal competencia ${ }^{23}$ y de protección al consumidor y las reglas de responsabilidad civil. ${ }^{24}$

Otra norma con rango de ley que debe ser tenida en consideración es el Decreto Legislativo 1448 de septiembre de 2018, cuyo artículo 5 señala que uno de los instrumentos para la mejora de la calidad regulatoria es el análisis de impacto regulatorio -identificado como RIA en la introducción del presente documento- ex ante y ex post..$^{25} \mathrm{El} \mathrm{RIA}$ es una herramienta usada para examinar y medir los probables efectos, costos y beneficios de una nueva o ya existente regu-

23. Y también sometida a la fiscalización del dumping y los subsidios, etcétera.

24. Sin perjuicio de respetar las demás normas que conforman el ordenamiento jurídico.

25. Decreto legislativo que modifica el artículo 2 del Decreto Legislativo 1310 - que aprueba medidas adicionales de simplificación administrativa-, y perfecciona el marco institucional y los instrumentos que rigen el proceso de mejora de calidad regulatoria, publicado en el diario oficial El Peruano el 16 de septiembre de 2018. 
lación. ${ }^{26}$ Es un proceso que permite identificar y evaluar sistemáticamente los efectos esperados de una propuesta regulatoria, utilizando un método analítico consistente, como es el análisis costo-beneficio - $\underline{A C B}$ - Es un instrumento que ayuda a asegurar que la regulación sea tan eficiente y efectiva como sea posible. Una regulación es efectiva -o idónea-si logra el objetivo de política que motivó su elaboración; y es eficiente si logra dicho objetivo al menor costo total para todos los miembros de la sociedad. ${ }^{27}$

Según el RIA, es aconsejable no emprender acción alguna —es decir, no regular- si el problema detectado es tan pequeño que no justifica los costos de la acción gubernamental, o cuando es bastante probable que ninguna regulación factible, u otra política pública, abordará el problema de manera efectiva y a un costo razonable en relación con el beneficio esperado de la regulación. ${ }^{28}$ Por tanto, una opción válida es no regular. Si cualquier opción regulatoria implica mayores costos que beneficios, lo mejor es abstenerse de regular. ${ }^{29}$ Mantener el statu quo es un escenario posible. No introducir medida regulatoria alguna es equivalente a dejar que siga funcionando el mecanismo de mercado, lo que significa que es preferible un mercado imperfecto - con las fallas que se hayan podido identificar- en lugar de una regulación imperfecta —con las ineficiencias o distorsiones que puede ocasionar-. ${ }^{30} \mathrm{Si}$ es más costoso para la sociedad una regulación imperfecta que un mercado imperfecto, debiera escogerse esto último. En consecuencia, no debe descartarse la alternativa "no hacer nada", considerando que muchas veces la solución estatal —la regulación — no es razonable, sea por generar mayores costos que beneficios, sea por no tener los efectos esperados, por lo que dejar que el mercado se corrija a sí mismo o soportar la falla del mercado es, a veces, una alternativa más razonable. ${ }^{31}$

En algunos casos, en lugar de una regulación directa de tipo comando y control, lo mejor es implementar otro tipo de acciones, como establecer campañas de información pública para educar y advertir a la población sobre el problema, proveer información específica a los consumidores que permita a estos cuidar de sus propios intereses, requerir a los proveedores de bienes o servicios dar información a los consumidores antes de que compren dichos bienes $y$ servicios, imponer un impuesto que desincentive una determinada actividad, aplicar subsidios para incentivar más el desarrollo de una conducta en particular, promover el desarrollo de esquemas de "auto regulación" dentro de una industria o grupo, ${ }^{32}$ entre otros.

26. Organisation for Economic Co-operation and Development (Regulatory Policy Division - Directorate for Public Governance and Territorial Development), Building an Institutional Framework for Regulatory Impact Analysis (RIA). Guidance for Policy Makers, OECD, versión 1.1, 2008, p. 7.

27. Organisation for Economic Co-operation and Development, Introductory Handbook for Undertaking Regulatory Impact Analysis (RIA), OECD, versión 1.0, octubre 2008, pp. 3 y 4.

28. Ibid, p. 5 .

29. Hugo Gómez Apac, Reflexiones sobre el Análisis de Impacto Regulatorio, en AA.VV. (Rubén Méndez Reátegui, Editor), Reflexiones Jurídicas. Vol. IV. Facultad de Jurisprudencia. (Centro de Publicaciones de la Pontificia Universidad Católica del Ecuador, Quito, 2018) P. 823.

30. Eduardo Quintana Sánchez, Análisis de Impacto Regulatorio en la Regulación Peruana de Servicios Públicos, en Revista Derecho \& Sociedad, Pontificia Universidad Católica del Perú, núm. 36, Lima, 2011, pp. 17 y 18.

31. Ministerio de Justicia y Derechos Humanos, Guía sobre el análisis de impacto regulatorio: Introducción a la evaluación post regulatoria, Ministerio de Justicia y Derechos Humanos, Lima, 2017, p. 30.

32. Organisation for Economic Co-operation and Development, Introductory Handbook..., p. 9. 


\section{CONCLUSIONES}

La regulación es una tarea inherente al estado que tiene por objeto evitar o minimizar que el inicio, desarrollo o cese de una actividad económica genere daños o externalidades negativas. Pero no se trata de regular por regular. La regulación debe ser eficaz y eficiente. Eficaz porque debe ser idónea para resolver el problema planteado. Eficiente porque debe ser la opción menos gravosa y debe tener más beneficios que costos.

Si no es posible implementar una regulación eficaz y eficiente, debe evaluarse la posibilidad de no regular la actividad. No debemos tener miedo al vacío regulatorio. La ausencia de regulación no significa ausencia de estado. Una actividad puede no estar regulada - ex ante-, pero el estado puede desplegar sobre ella otros tipos de intervención ex post, como sancionar las conductas anticompetitivas, los actos de competencia desleal y las infracciones a las normas de protección al consumidor, así como dotar de efectividad a las reglas de responsabilidad civil. ${ }^{33}$

Instrumentos que nos ayudan a mejorar los es- ADMERINTRATIVO quemas regulatorios son el test de razonabilidad, el régimen de eliminación de barreras burocráticas y el análisis de impacto regulatorio, y estos dos últimos instrumentos aceptan como una alternativa de parte del hacedor de políticas públicas el no regular una determinada actividad económica. Es preferible que no haya regulación a que esta tenga más costos que beneficios.

A la pregunta de si toda actividad económica debe estar regulada, la respuesta concedida en el presente ensayo es que no, que es factible sostener que algunas actividades económicas podrían estar exentas de regulación.

33. Para que, por ejemplo, las personas en su condición de víctimas sean auténticamente resarcidas por la ocurrencia de accidentes, por la compra de productos defectuosos, por el daño proveniente de la contaminación, etc. 